\title{
Governance Assessment of the Leader Approach in Calabria Using an Integrated AHP - Fuzzy TOPSIS Methodology
}

\author{
Giuseppa Romeo ${ }^{1, a}$, Claudio Marcianò ${ }^{1, b}$ \\ ${ }^{1}$ Mediterranean University of Reggio Calabria, Agraria Department, \\ Feo de Vito, 89122 Reggio Calabria, Italy \\ agiuseppa.romeo@unirc.it, bclaudio.marciano@unirc.it
}

Keywords: Rural Governance, Leader Approach, AHP, Fuzzy TOPSIS.

\begin{abstract}
The paper carries out an evaluation of the performance of the development process of Leader Approach in the Rural Development Programme 2007-2013 in Calabria. An appropriate set of process indicators have been identified and measured in order to evaluate the procedures and actions practiced by Local Action Groups (LAG) in the planning phase of the Local Development Plans. Those indicators have been employed to construct an evaluation tree through which the performance of each LAG is tested and compared to an ideal model of "Good Governance" through the application of an integrated multicriteria methodology based on Analytic Hierarchy Process (AHP) and fuzzy Technique for Order Performance by Similarity to Ideal Solution (fuzzy-TOPSIS). The results outline a possible model for evaluating the quality of the integrated planning process of the LAGs, pointing out eventual elements of criticism and virtuous behaviours.
\end{abstract}

\section{Introduction}

In the last twenty years the European Community has identified in the LEADER the most suitable instrument to promote the integrated development of the rural areas so that, in the 2007-2013 EU planning period, it lost its experimental modality of "laboratory" to assume the "approach" one. The Local Action Groups (LAGs), as an expression of the Partnership, are deputed to favour the concertative meeting among the public, private and social components of the territory, in order to define the strategies to be adopted in the Local Development Plans (LDP). In this process, the Partnership becomes the organizational form of the institutional model of governance which, by involving the local actors of development and the civil society, represents a modality potentiating the quality of public policies and their probabilities of success, widening the consensus and the responsibility of each partner [1]. However, the will of enforcing the dimension of the participatory democracy, felt at a European level, through a greater involvement of the civil society in the decision-making process, has contributed to develop the normative concept of 'Good Governance' (GG) [2] which, in the "White Paper", is focused on five principles: opening, participation, responsibility, effectiveness, coherence.

The literature offers us various studies aimed mainly at evaluating the results and the impact of the policies worked out by the partnerships; on the contrary, it is noticed a lack of studies analyzing the activities and the relations characterizing the planning phase of local development strategies.

Therefore, the choice of focusing on the planning phase has as purpose the analysis and the assessment of the different aspects with which the partnerships have operated, in order to determine and formulate development actions. This is motivated by the assumption according to which the result of a process depends largely on the quality of the same planning process [3].

On the basis of such preconditions, the analysis of the elaboration process of the LDP represents a first useful step to understand how the LAGs have been thinking and organizing a development process in their own territory. In this context, the present study has as purpose an evaluating analysis of the performance of the development process of the Leader approach in the Rural Development Programme 2007-2013 in Calabria and the empirical part of the study assesses how the LAGs have been using the existing planning instruments. 
In particular, we want to measure and evaluate the application of the GG criteria, by using an appropriate set of process indicators $[4,5]$, procedures and actions practiced by LAGs in Calabria to reach the purposes of the program. These indicators will be employed to build the tree evaluation through which the performance of each LAG will be tested compared to an ideal model of "Good Governance". In the first step they have been singled out the conceptual framework of criteria (key-dimensions) and the sub-criteria (sub-dimensions) of the GG. The concept of GG has been subdivided into seven dimensions and 39 sub-dimensions, identified to facilitate the individuation of the process indicators.

Following are listed the dimensions identified:

- Social capital: it is particularly important to understand how the collective actions have been carried out [6] and to verify if the strategies have been integrated and shared on the basis of the principles of co-partnership and cooperation which, through the synergic action, strengthen the production capacity of the same territory $[7,8,9,10]$.

- Efficiency: refers to the advantages of the information acquired by the decisional makers involved in the planning phase, since this information is very important in order to develop a strategy based on territorial needs. Since the acquisition of information reduces the margin of uncertainty on the choices, the research of information is intended as one of the main factors of the GG's organizational factors [11].

- Effectiveness: the partnership's effectiveness is generally measured through its own capacity to reach a certain goal. Since in the planning phase the economic indicators are not enough to determine the partnership's effectiveness [11], such a dimension refers to the partnership's actors' ability to avoid conflict escalation, to reduce the less constructive conflicts and, at the same time, to optimize the exchange of knowledge and information necessary to produce and carry out effective and joint decisions.

- Participation: the principle of participation derives from the acknowledgment of the fact that the community is the heart of integrated development [12]. Participation refers to the necessity to involve in the decisional making process both the stakeholders and the local communities. So, participation gets a role of functional utility, because it allows to use learning capacity of the stakeholders and give them voice in the identification and in the development interventions planning, fitting the effective needs of the territory.

- Transparency: the transparency is referred to the decision process, assuring that information is freely available for all those who are involved or interested in the decisions taken. So, transparency means free access to the information [13].

- Accountability: the accountability reflects the values of democracy [14] and it is linked to the responsibilities each actor holds in the activities he is involved in [15]. In particular, such dimension focuses on the role and the degree of influence the actors take on in the decision process.

- Sustainability: the sustainability concerns the partnership's ability to build up policies projected in a medium and long-term period vision and do not exhaust their utility with the end of the planning cycle. Within this strategic view it is important to be able to mobilize both private capitals and, more, actors of the local entrepreneurial network to let the LDP policies create a synergy with those of other plans.

For each sub-criterion it has been identified a quantitative or a qualitative indicator, the origin of which came out from an initial analysis of the literature, the transformation of the information gathered through interviews to experts and from the definition of new indicators [4,5]. Appropriate scales of measurement have been associated to the indicators of qualitative nature. In the second step, after the indicators' measurement, the conceptual frame designed before has been used to build the evaluation tree of the performance of the rural governance within the fields of the Leader approach.

For this purpose, we went on with the implementation of the Analytic Hierarchy Process (AHP) and fuzzy Technique for Order Performance by Similarity to Ideal Solution (fuzzy-TOPSIS) multi-criteria integrated model. With the first technique the weighing of the good governance criteria 
has been carried out, while through fuzzy TOPSIS it has been got the ranking of the performance of the rural governances under examination.

\section{Methodology}

The methodology is based on an integrated multicriteria model which combines two techniques: Analytic Hierarchy Process (AHP) [16] and fuzzy Technique for Order Performance by Similarity to Ideal Solution (fuzzy-TOPSIS) [17, 18].

The AHP is a Multiple Criteria Decision Making (MCDM) method which is carried out building a hierarchical tree structured in more levels, the number of which grows according to the level of data disaggregation. The evaluation tree is composed of four levels: goals, criteria, sub-criteria and alternatives; in the examined case, the last one is coincident with the LAGs. After the decisional tree "building", the criteria have been submitted to pairwise comparisons through a questionnaire. This has allowed to the experts to express their judgement and to compile pairwise comparison matrices. The eleven experts interviewed are represented by technical directors or the presidents of the examined LAGs. In a previous study it was seen a high variability in the judgments made by the experts on the importance of the GG dimension [5]. This variability was not properly taken into account using average weights derived from AHP. In order to resolve this ambiguity, often arising from human judgments, it was preferred to aggregate the weights through fuzzy triangular numbers [19] and then ranking the alternatives with the TOPSIS method, which select as optimal alternative the closest solution to the ideal one and farthest solution from the negative ideal one.

The fuzzy TOPSIS was developed by Chen and Hwang [17] in order to evaluate relative closeness for each alternative through fuzzy arithmetic operations. TOPSIS, and can be described as follows: Step 1- Compute aggregate fuzzy ratings for the criteria and the alternatives.

A panel of decision-maker has $\mathrm{K}$ members $D(1, \ldots, K)$ which are responsible of ranking the alternatives $\mathrm{A}=\left\{\mathrm{A}_{1}, \mathrm{~A}_{2}, \ldots, \mathrm{A}_{\mathrm{m}}\right\}$ with respect to $n$ criteria $C_{i}=\left\{C_{1}, C_{2}, \ldots C_{\mathrm{n}}\right\}$ and the relative weights denoted by $w_{i}(i=1, \ldots, n)$. Then the aggregated fuzzy criteria weights can be described as triangular fuzzy number:

$\widetilde{w_{i}}=\left(a_{i}, b_{i}, c_{i}\right)$, determined as follow:

$$
a_{i}=\min _{k}\left\{a_{i, k}\right\}, \quad b_{i}=\frac{1}{K} \sum_{k=1}^{k} a_{i, k}, \quad c_{i}=\max _{k}\left\{a_{i, k}\right\}
$$

The aggregated fuzzy importance weight for each criterion is normalised as follow:

$$
\widetilde{w_{j}}=\left(w_{j 1}, w_{j 2}, w_{j 3}\right)
$$

Where:

$$
w_{j 1}=\frac{\frac{1}{a_{i}}}{\sum_{i=1}^{n} \frac{1}{a_{i}}}, w_{j 2}=\frac{\frac{1}{b_{i}}}{\sum_{i=1}^{n} \frac{1}{b_{i}}}, \quad w_{j 3}=\frac{\frac{1}{c_{i}}}{\sum_{i=1}^{n} \frac{1}{c_{i}}}
$$

The normalized aggregated fuzzy importance weight matrix is given by:

$\widetilde{W^{\prime}}=\left[\widetilde{w_{1}}, \widetilde{w_{2}}, \ldots, \widetilde{w_{3}}\right]$

Step 2- Decision matrix construction 
Creating an evaluation matrix $D\left[x_{i j}\right]_{m x n}$ where $x_{i j}$ is the evaluation of alternative $A_{i}$ for criterion $C_{j}$. Qualitative or quantitative values are assigned to the criteria employed for each level of the built decisional tree.

Step 3- Normalized Decision matrix

The $\mathrm{D}\left[\mathrm{x}_{\mathrm{ij}}\right]_{\mathrm{mxn}}$ decisional matrix values are normalized through the following equations:

$r_{i, j}=\frac{x_{i j}}{\sqrt{\sum_{j=1}^{n} x_{i j}^{2}}} \quad$ for benefit criteria

$r_{i, j}=\frac{\frac{1}{x_{i j}}}{\sqrt{\sum_{j=1}^{n} x_{i j}^{2}}} \quad$ for cost criteria

where

$\mathrm{i}=1,2, \ldots, \mathrm{m}$ and $\mathrm{j}=1,2, \ldots, \mathrm{n}$

Step 4- weighted normalized decision matrix

The columns of the normalized decision matrix are multiplied for the weights, $\widetilde{w_{\imath}}$, obtained with Eq. 2. The weighted normalized decision matrix $\tilde{V}$ for each criterion is defined as:

$\tilde{V}=\left[\tilde{v}_{i j}\right]_{m x n} \quad$ for $\quad \mathrm{i}=1,2, \ldots, \mathrm{m}$ and $\mathrm{j}=1,2, \ldots, \mathrm{n}$

where

$$
\tilde{v_{i j}}=r_{i j} \times \tilde{w}_{i}
$$

Step 5: Determine the fuzzy Positive Ideal Solution (PIS) using equation (6) and the fuzzy Negative Ideal Solution (NIS) using equation (7):

$$
\widetilde{A^{*}}=\left(\widetilde{v_{1}^{*}}, \widetilde{v_{2}^{*}}, \widetilde{v_{n}^{*}}\right)
$$

where

$$
\begin{aligned}
& \widetilde{v_{j}^{*}}=\left(\max _{i}\left(v_{i j 1}\right), \max _{i}\left(v_{i j 2}\right), \max _{i}\left(v_{i j 3}\right)\right) \\
& \widetilde{A^{*}}=\left(\widetilde{v_{1}^{-}}, \widetilde{v_{2}^{-}}, \widetilde{v_{n}^{\prime}}\right)
\end{aligned}
$$

where

$$
\widetilde{v_{j}}=\left(\min _{i}\left(v_{i j 1}\right), \min _{i}\left(v_{i j 2}\right), \min _{i}\left(v_{i j 3}\right)\right)
$$

for $i=1,2, \ldots, m$ and $j=1,2, \ldots, n$

Step 6: Calculating the Euclidean distance:

The distance from ideal, PIS, and anti ideal solutions, NIS, are measured. The two Euclidean distances for each alternative are computed respectively:

$$
\widetilde{d_{i}^{*}}=\sqrt{\sum_{j=1}^{n}\left(\widetilde{v_{\imath j}}-\widetilde{v_{j}^{*}}\right)^{2}} \quad \text { for } \mathrm{i}=1,2, \ldots, \mathrm{m}
$$




$$
\widetilde{d}_{i}^{-}=\sqrt{\sum_{j=1}^{n}\left(\widetilde{v_{\imath j}}-\widetilde{v}_{j}^{-}\right)^{2}} \quad \text { for } \mathrm{i}=1,2, \ldots, \mathrm{m}
$$

Step 7: Calculating the fuzzy closeness coefficient $\tilde{C} C_{i}$ :

$$
\tilde{C} C_{i}=\frac{\widetilde{d_{i}^{*}}}{\widetilde{d_{i}^{*}+\widetilde{d_{i}^{*}}}} \quad \text { for } \mathrm{i}=1,2, \ldots, \mathrm{m}
$$

Step 8: Calculating the defuzzified closeness coefficient:

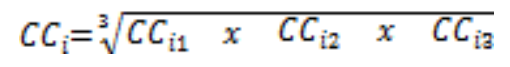

The values of $\mathrm{CC}_{\mathrm{i}}$ are used to determine the final ranking.

\section{Results}

The model assessment provides a framework for the ranking of the rural governance performance dealing with the Leader Approach in the 2007-2013 Rural Development Programme in Calabria. In the application of fuzzy TOPSIS method, the aggregated fuzzy weights of each criterion are calculated using Eq.1 and then they are normalized using Eq.2. The results are shown on table 1.

Table 1 - Normalized aggregate fuzzy criteria weight

\begin{tabular}{lccc} 
Criteria & $\mathrm{W}_{\mathrm{j} 1}$ & $\mathrm{~W}_{\mathrm{j} 2}$ & $\mathrm{~W}_{\mathrm{j} 3}$ \\
\hline Social Capital & 0,2580 & 0,1950 & 0,1396 \\
Efficiency & 0,0967 & 0,1545 & 0,1774 \\
Effectiveness & 0,0817 & 0,1150 & 0,1231 \\
Participation & 0,0878 & 0,1254 & 0,1260 \\
Transparency & 0,1971 & 0,1337 & 0,1498 \\
Accountability & 0,1121 & 0,1483 & 0,1613 \\
Sustainability & 0,1666 & 0,1280 & 0,1228 \\
Total & 1,0000 & 1,0000 & 1,0000 \\
\hline \multicolumn{3}{c}{ Source: Our elaboration }
\end{tabular}

In the next steps the decisional matrix is formed and normalized (Eq.3 e 4). Next the fuzzy weighted decision matrix for the alternatives, which in the study correspond to the 11 LAGS, is calculated using equation 5. After the fuzzy positive $\widetilde{A^{*}}$ and negative $\widetilde{A^{-}}$ideal solution is calculated using Eq. 6 e 7. Then, the fuzzy distance of each LAG from the fuzzy positive ideal matrix $\widetilde{d_{i}^{*}}$ and fuzzy ideal negative matrix $\widetilde{d_{i}^{-}}$are computed respectively with Eq. 8 e 9, and with Eq. 10 we compute the fuzzy closeness coefficients $\left(\tilde{C} C_{i}\right)$. Finally, with Eq.11 the defuzzification procedure has been applied in order to determine the defuzzified closeness coefficients (CCi) which are used to rank the alternatives (tab.2).

LAG-2 and LAG-7 are those showing the best performances with respect to the GG ideal model, designed around the pointed out criteria. It is interesting to notice the meaningful gap existing between these two LAGs and the remaining ones. Among the other LAGs, it is possible to observe lower differences and in particular, LAGs 8 and 5 are the ones showing the lowest performances respectively with 0,00013 and 0,00001 . Moreover, it must be underlined that the carried out analysis 
does not want to reach a strict ranking on the state of performance of the LDP's planning process adopted by the LAGs. Indeed, its main purpose is to provide input for discussion, in order to point out the elements which could favour or obstruct the achievement of ideal performances.

Table 2 -Fuzzy closeness coefficients and final ranking on the basis of the defuzzified closeness coefficient (Cci)

\begin{tabular}{lcccc}
\hline LAGS & $\mathrm{CC}_{\mathrm{i} 1}$ & $\mathrm{CC}_{\mathrm{i} 2}$ & $\mathrm{CC}_{\mathrm{i} 3}$ & $\mathrm{CC}_{\mathrm{i}}$ \\
\hline LAG-2 & 1,56450 & 1,49833 & 2,20676 & 1,72432 \\
LAG-7 & 1,78738 & 1,22768 & 1,02550 & 0,75009 \\
LAG-1 & 0,18384 & 0,48003 & 0,40659 & 0,01196 \\
LAG-4 & 0,14075 & 0,28138 & 0,27339 & 0,00361 \\
LAG-11 & 0,11967 & 0,26902 & 0,25681 & 0,00276 \\
LAG-9 & 0,16703 & 0,15291 & 0,12246 & 0,00104 \\
LAG-6 & 0,05105 & 0,17022 & 0,20608 & 0,00060 \\
LAG-3 & 0,05506 & 0,12769 & 0,12931 & 0,00030 \\
LAG-10 & 0,05385 & 0,10506 & 0,08996 & 0,00017 \\
LAG-8 & 0,08771 & 0,07480 & 0,05955 & 0,00013 \\
LAG-5 & 0,03169 & 0,02366 & 0,02112 & 0,00001 \\
\hline \multicolumn{5}{c}{ Source: Our elaboration }
\end{tabular}

\section{Discussion}

The assessment model proposed in this paper uses an integrated method of AHP and fuzzy TOPSIS to provide a framework for the ranking of the rural governance performance dealing with the Leader Approach in the 2007-2013 Rural Development Programme in Calabria. Specifically, of the fourteen LAGs selected from Calabria Region they were taken eleven into consideration. More in detail, the AHP method has been applied to obtain the weight of the single criteria while the fuzzy TOPSIS method leads to the ranking of Local Action Groups' performances. This study intends to give a contribution to the matter of the assessment of rural policies, providing a fact-finding contribution on the performance of the organizational and interactive modalities adopted during the phase of planning within the partnership process of the Leader Approach. The used methodology appears as an efficient instrument to evaluate how performance of the rural planning of the LAGs differs with respect to an ideal GG model elaborated on the criteria of Social Capital, Efficiency, Effectiveness, Participation, Accountability and Sustainability and on the 39 sub-criteria linked to them. The AHP-fuzzy TOPSIS methodology presents some advantages. First of all, the fuzzy approach enables to model real life situations which cannot be properly taken into account with crisp data, given the presence of vague human judgments. Indeed, the weighting process of criteria involve a high variability of judgments by the experts that cannot be represented with exact numeric values. Second one, the individuation of the synthetic index of the performance score $\left(\mathrm{CC}_{\mathrm{i}}\right)$ allowed aggregation and comparison of the final results among the single LAGs, which makes more immediate the communication of the results to policy makers at the regional level and to the LAGs.

One future step of the research is to proceed with the comparison between the results of the performance of the phase of the LDP planning process and the results of the carrying out performance of the following implementation phase. 


\section{References}

[1] AA.VV., Il processo partenariale nella nuova fase di progettazione integrata in Sardegna, Formez, Rome ( 2007)

[2] CE, European Governance: A White Paper. European Commission (2001)

[3] D. Reeb: Towards the development of criteria and indicators to assess the level of participation in NFP processes. The evaluation of forest policies and programmes, EFI Proceedings n. 52 (2004) 87-102

[4] G. Romeo and C. Marcianò: Una valutazione multicriteriale del processo di pianificazione delle governance rurali nell 'Approccio Leader in Calabria, in C. Marcianò (Ed.), Governance rurali in Calabria, Università degli Studi Mediterranea di Reggio Calabria, Centro Stampa di Ateneo, (2013)

[5] G. Romeo and C. Marcianò: Evaluating the performance of rural governance in Calabria, 133nd EAEE Seminar, Chania, Crete (Greece), June 15-16, 2013

[6] G. Cundill and C. Fabricius: Monitoring the governance dimension of natural resource comanagement, Ecology and Society, 15 (2010) 1: 15

[7] G. Franceschetti (Ed.): Capitale sociale e sviluppo rurale. La potenzialità dell'approccio LEADER e la sua trasferibilità, CLEUP SC, Padova (2009)

[8] G. Nardone, R. Sisto, and A. Lopolito: Social Capital in the LEADER Initiative: a methodological approach, Journal of Rural Studies, 26 (2010) pp. 63-72.

[9] A. Lopolito, G. Giannoccaro and M. Prosperi: Efficiency of LEADER Programmes in the creation of tangible and intangible outputs: a Data Envelopment Analysis application to Local Action Groups performances, 122nd EAAE Seminar, Ancona (Italy), February 17-18, 2011.

[10] C. Marcianò and M. Palladino: La pianificazione integrata in un'area calabrese nell'ottica di una rete di affiliazione, in $\mathrm{C}$. Marcianò (Ed.), Governance rurali in Calabria, Università degli Studi Mediterranea di Reggio Calabria, Centro Stampa di Ateneo (2013)

[11] M. M. Augustyn and T. Knowles: Performance of tourism partnerships: a focus on York, Tourism Management, 21 (2000) pp. 341-351.

[12] M. Srivastava, Good Governance-Concept, Meanong and Features: A Detailed Study, (2009), Available at SSRN: http://ssrn.com/abstract=1528449 or http://dx.doi.org/10.2139/ssrn.1528449

[13] M. Căluşer and M. Sălăgean (Eds.): Good Governance in Multiethnic Communities: Conditions, Instruments, best practices, ways to achieve and measure good governance at the local level, A joint publication of the Ethnocultural Diversity Resource Center amd the King Baudouin Foundation, Belgium (2009)

[14] K. Callan: Elements of Effective Governance. Measurement, Accountability and Partecipation, Taylor \& Francis Group (2007)

[15] M. K. McCall, and C.E. Dunn: Geo-information tools for participatory spatial planning:Fulfilling the criteria for 'good' governance?, Geoforum, 43(2012) pp. 81-94.

[16] T. L. Saaty: Mathematical Methods of Operations Research, Dover Publications, New York (1988)

[17] S. J. Chen and C.L. Hwang: Fuzzy multi attribute decision making, Lecture Notes in Economics and Mathematical System, Springer-Verlag, Berlin, vol. 375, (1992)

[18] C.T. Chen: Extension of the TOPSIS for group decision-making under fuzzy environment. Fuzzy Sets and Systems, 114 (2000) pp.1-9.

[19] Y. J. Lai and C. L. Hwang: Fuzzy mathematical programming, methods and applications, Lecture Notes in Economics and Mathematical System, Springer-Verlag, Berlin, vol. 394, (1992) 